\title{
Experimental case study on the effect of the urban morphology on urban microclimate and outdoor thermal comfort
}

\author{
Sedira $\mathrm{S}^{1}$, Mazouz S 2,*
}

1 Laboratory of design and modelling of forms and environments, Department of architecture, University of mouhamed khider Biskra,Algeria.

2 Department of architecture. University of Larbi Ben Mhidi, Oum Bouaghi, Algeria.

* Corresponding Author: sedirasara@gmail.com

Received: 20-02-2018

Revised: 28-05-2018

Accepted: 03-06-2018

\begin{abstract}
The present study aims at testing the influence of the urban morphology on the external weather conditions and the urban microclimate by treating quantitative aspects of the outdoor thermal comfort. This is based on a site investigation aims at studying the correlation between the geometry of the street, its orientation and the evolution of the physical variables: air temperature (Ta), Mean Radiant Temperature (MRT), Relative Humidity (RH), Wind speed (Ws).The measures were the subject of a campaign carried out in the urban fabric of the ksar of the red village in the wilaya of Biskra in Algeria. The objective is to define the most efficient urban geometry in term of summer thermal comfort by studying the real impacts of the urban form on the solar control and microclimatic conditions. The evaluation of the thermal comfort in these external spaces is carried out by analyzing physiologically equivalent temperature (PET) values calculated by Rayman Pro 2.1 software based on the measured microclimatic parameters.
\end{abstract}

Key words: urban morphology; urban microclimate; outdoor thermal comfort; warm and arid climate; mean radiant temperature.

\section{Introduction}

For several decades, the influence of climatological parameters on the comfort conditions at the urban scale has motivated a great deal of research. Urban climatology specialists have sought to evaluate the thermal comfort in outdoor spaces, which has acquired its acclaim and becomes of similar importance to interior comfort, widely discussed (Ali-Toudert et al., 2005-a; Ali-Toudert et al., 2005-b; Bourbia et al., 2004; Johansson, 2006; Stathopoulos et al., 2004).

Outdoor human comfort in an urban climate may be affected by a wide range of weather and human factors, including wind speed, air temperature, relative humidity, solar radiation, air quality, human activity, clothing level, age, etc . Urban climatology has evolved research on the correlation between urban form, morphological characteristics, materials and the urban microclimate by accommodating specific and diversified methods.

According to the different modes of adaptation of the human body, physical adaptation, physiological and psychological (Ouameur, 2007). Researchers specialized in urban climatology have developed a number of approaches and methods for evaluation, concluding that thermal comfort is not only influenced by physiological responses to the regulatory system via the microclimatic variables but also by the inevitable psychological and social adaptation, which shows the degree of adaptation of the users to the external conditions, considering that the adoption of the physiological approach alone is not sufficient for a convincing and reliable evaluation of the Thermal comfort in an outdoor space (Makaremi et al., 2012; Louafi et al., 2013).

In most outdoors thermal comfort studies, a purely physiological model has been used, involving a mathematical model of the thermoregulatory system employed for calculating the thermal comfort conditions, whereas the subjective responses have not been considered. Thermal comfort in outdoor spaces is a complex and global notion because of the multiplicity of parameters that interact and influence its evaluation, taking into account both objective and 
subjective factors, (Nikolopoulou et al. , 2001) and translated by psychological factors such as: past experiences, perceived control, time of exposure, environmental stimulation, expectations and naturalness (Nikolopoulou et al. , 2003).

The effect of physical adaptation can be evaluated numerically. Physical adaptation involves all the changes a person makes, in order to adjust oneself to the environment, or alter the environment to his needs. Thus, Physiological adaptation implies changes in the physiological responses resulting from repeated exposure to a stimulus, leading to a gradual decreased strain from such exposure. In the context of the thermal environment, this is called physiological acclimatization. The physical environment and psychological adaptation is argued to be complementary rather than contradictory, and consideration of this duality could increase the use of the outdoor spaces (Nikolopoulou et al., 2003).

\section{Case study}

The Dachra El Hamra (the red village) is a traditional fabric of the pre-colonial era. It is the first nucleus of El Kantara which, through its opening on the desert and by its richness in date palms (more than 50000), constitutes the portal of the transition between two regions whose climatic aspects are quite different: the north And the south of Algeria. It is an oasis located in the wilaya of Biskra to $50 \mathrm{~km}$ to the north of the city and in the Southwest of the Aures to $80 \mathrm{~km}$ of Batna, (Hamouda et al., 2013).

The Dachra El Hamra is a compact entity characterized by a densely populated urban fabric with narrow, unpaved streets and a dominant type of habitat built in the Saharan architectural style. The streets, the narrow streets, the deep canyons, cul-de-sac (Darb), the covered passages (Skifa), squares (Rahba or Batha) constitutes the elements of the structure designed according to the style of the old towns (Ksour) The introverted model of the Arab-Islamic medina (Hamouda et al., 2011).

This region is characterized mainly by the aridity of her climate, high summer daytime temperatures, large diurnal temperature range, and high solar radiation.

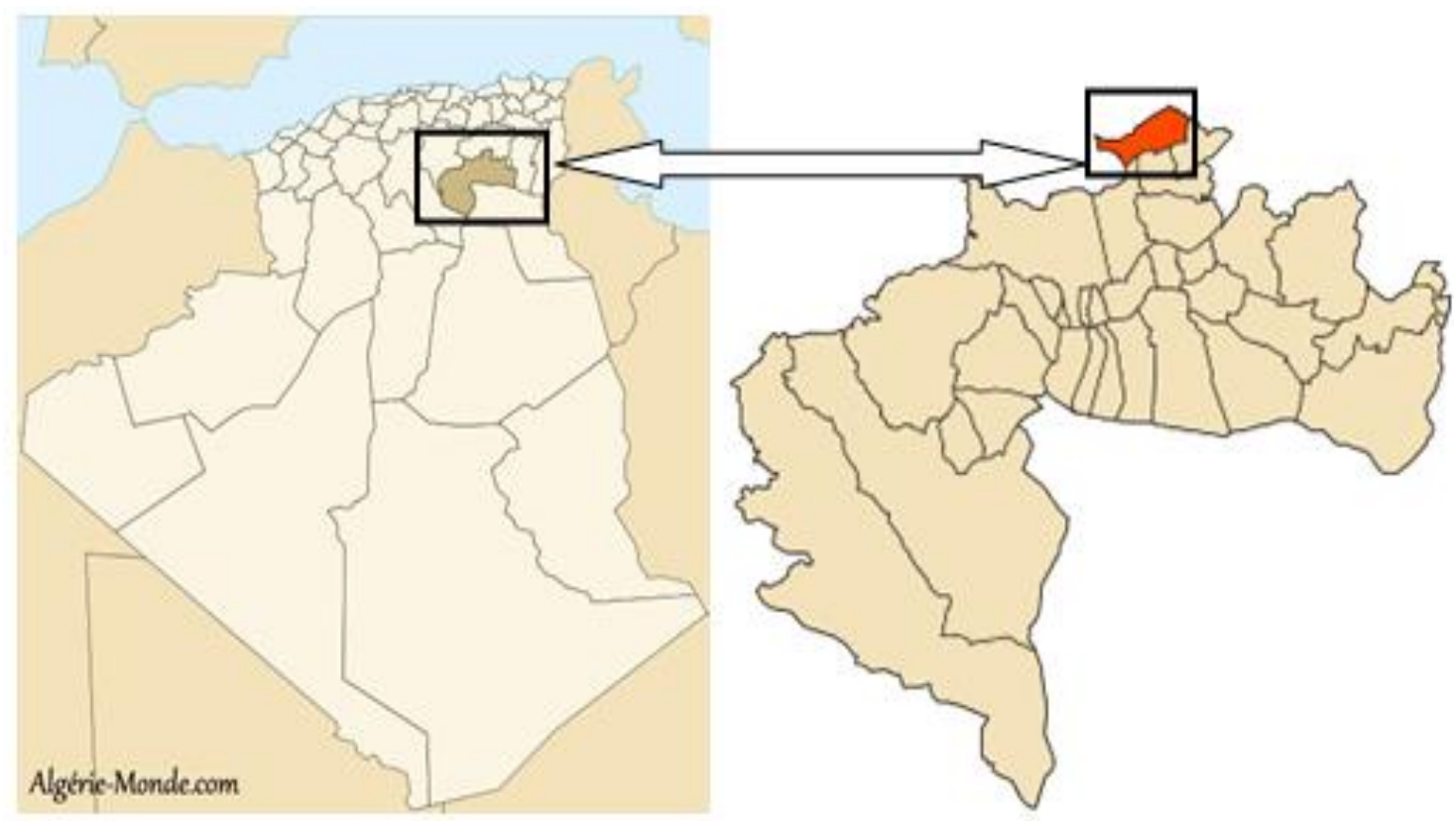

Fig 1. The administrative card of Algeria (In the left) and the localization of el Kantara in the wilaya de Biskra (in the right). 


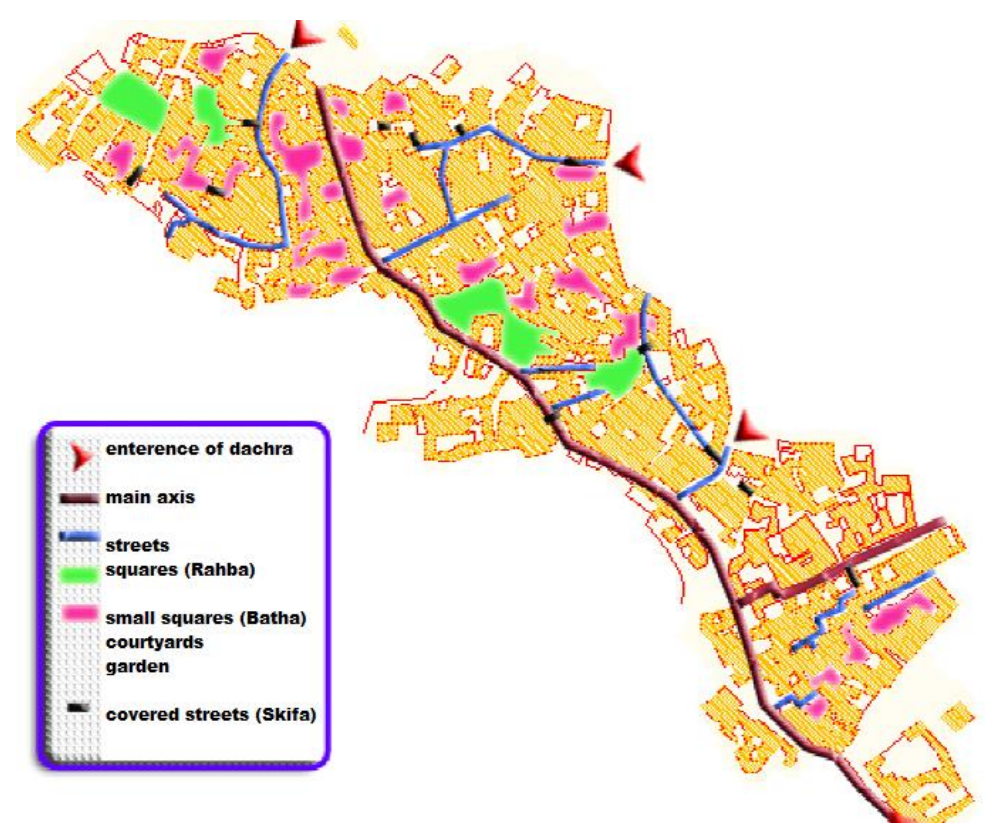

Fig 2. The urban morphology of the Dachra.

\section{Methods}

In order to determine the mean radiant temperature (MRT) required for the calculation of PET, the index adopted for the evaluation of thermal comfort in the study site, it is inevitable to examine the four main climatic parameters previously cited, of the instrument: "TESTO data logger $480 "$ whereby the air temperature, relative humidity, wind speed and the temperature of a globe thermometer.

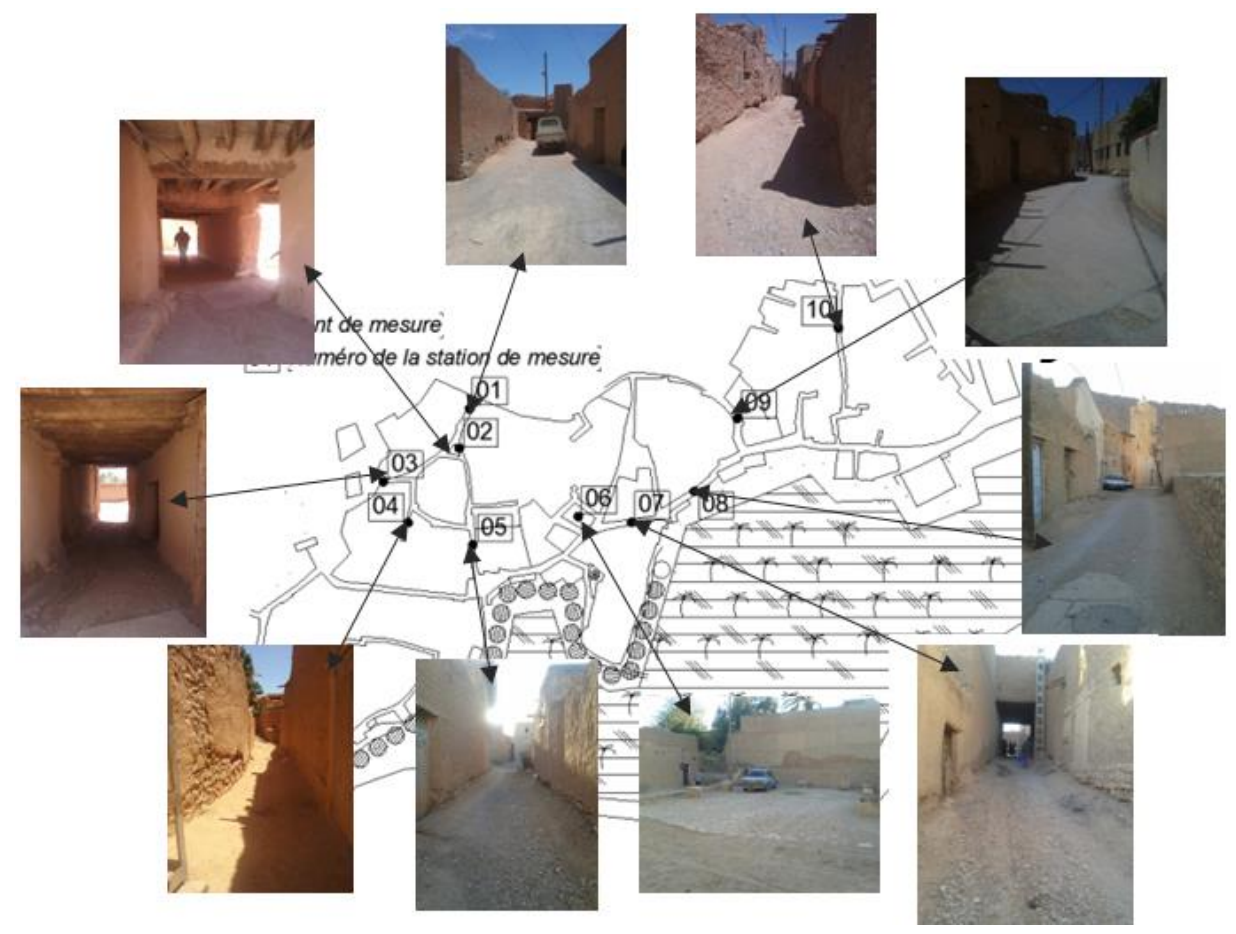

Fig 3. The Localization of measured points. 
Table 1. Representation of geometrical characteristics of measured points.

The investigations of this study are limited to the summer period of a meteorological data series (2006-2015), because climatic heat stress in the urban open spaces mainly occurs during this season. Conversely, thermal cold stress only occurs in winter for a few days between 27 July and 04 August is where the thermal stress reaches its maximum values. During this period, 29 and 30 July were chosen for the elaboration of the investigation and considering the days with the typical summer conditions.

The selection of measurement points is the result of a typo morphological analysis of the urban fabric of the case study, in order to identify the different typologies existing in the external space. These points were localized in (Figure 3), presented and described in Table 1.

Table 2. Representation of geometrical characteristics of measured points.

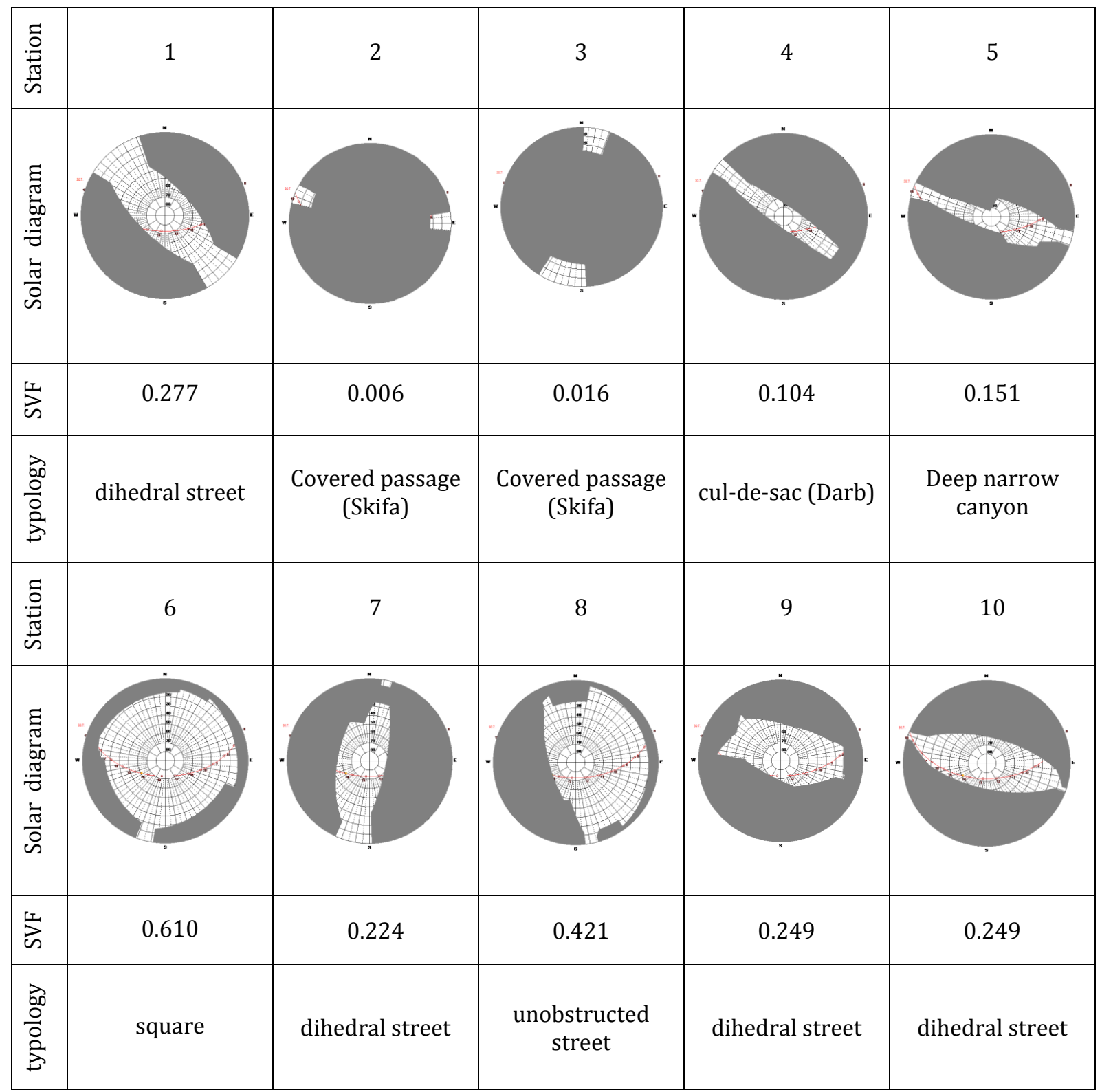




\section{Results and discussion}

\subsection{Impact of the urban geometry on mean radiant temperatures}

The mean radiant temperature reaches its maximum value in point six (06) where the lowest $\mathrm{H} / \mathrm{W}$ ratio (The ratio: height of building / wide of street) was recorded with a considerable difference with the temperature of the air measured under the effect of the sunshine (Figure 4). As well as recording low values in points with a high $\mathrm{H} / \mathrm{W}$ ratio or in the covered passages where the graph begins to decrease, this difference relates to exposure to solar radiation, according to which points Exhibits a small gap are the least exposed.

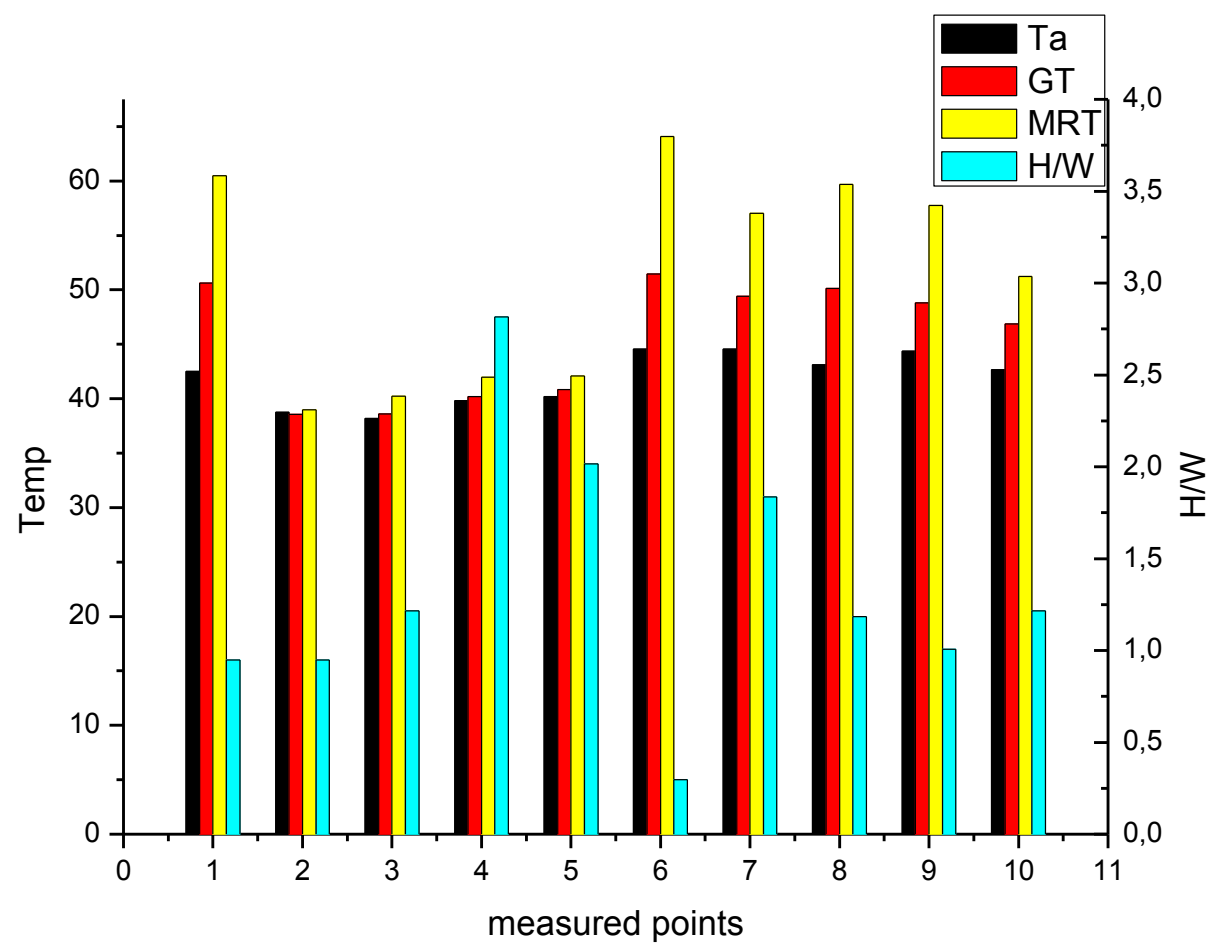

Fig 4. Mean radiant temperature measured in different points at 29-30/07/2016.

\subsection{Impacts of the physiologically equivalent temperature}

The evaluation of the values of the physiological equivalent temperature presented in the graph (Figure 5), we note the relationship between PET and MTR, the increase of MRT of which leads to an increase in PET values. It is also remarkable that the values of MRT and PET vary simultaneously with the variation in the values of the SVF (presented above in Table 1), the increase of which leads to an increase in the values of this index, the maximum value at point 06 with the highest SVF. In addition, the minimum values for PET were recorded under the covered passages thanks to the shadow generated by the latter at the street level. The considerable difference between the SVF of the two points 07 and 08 did not result in a large difference between the values of the PET recorded there, thanks to the solar orientation of the point 08 which presents the highest SVF. The solar orientation also has a considerable effect when comparing the two points 09 and 10 which have the same SVF and an apparent deviation from the values of the PET, finding that the point 10 oriented North- West. 


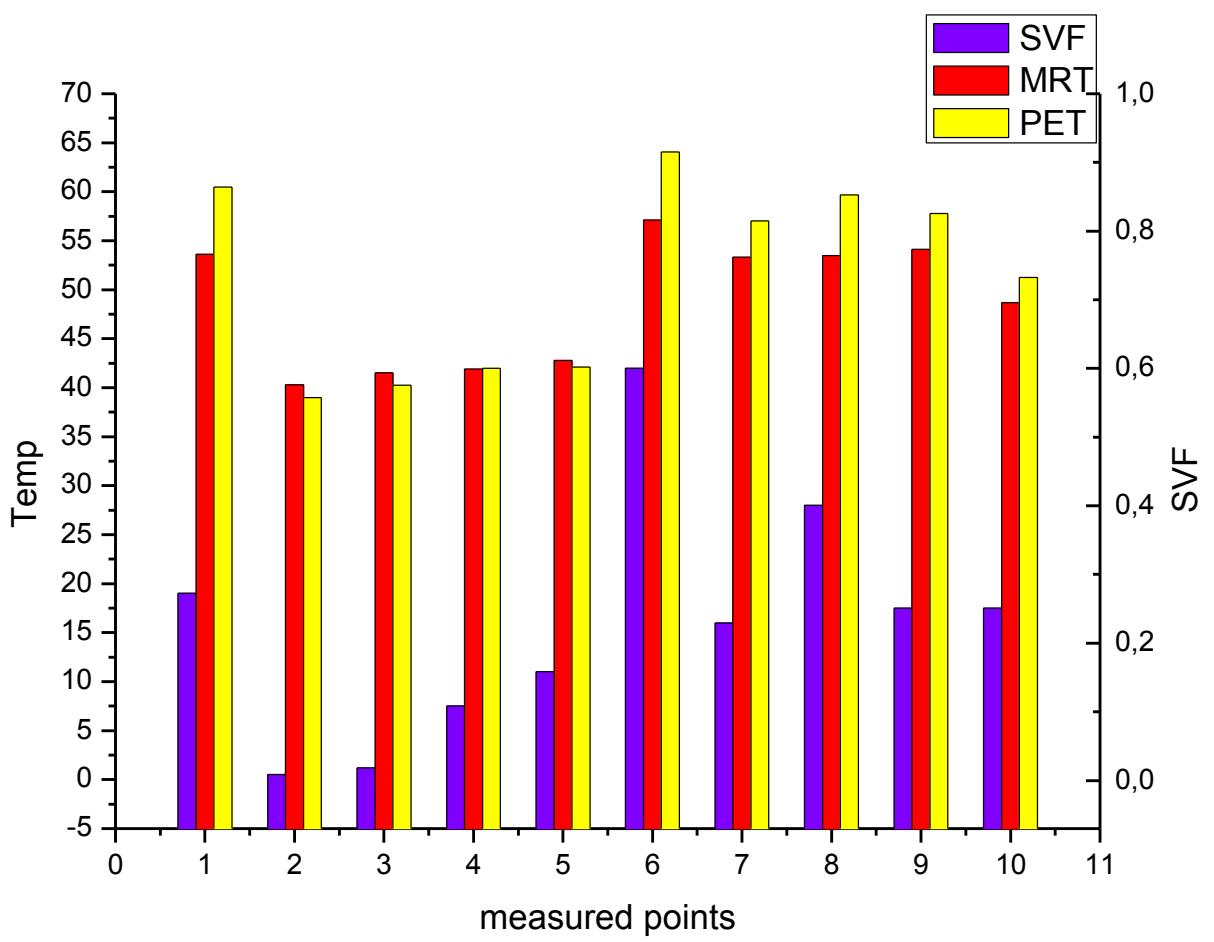

Fig 5. The physiologically equivalent temperature calculated PET values measured in different points at 29-30/07/2016.

\section{Conclusion}

This study shows that a compact urban form with deep street canyons provides a good protection during the hot days of summer period, this typology of streets combined with covered passages provides shade for pedestrians during the warmest period of the day. The study of the above graphs in relation to the geometrical characteristics of the points studied, represented in Table 1, and enabled us to reach a certain number of recommendations relating to urban design in hot regions. The analysis of the acquired results of the investigation allowed us to demonstrate the considerable effect of SVF, the ratio H/W and the solar orientation on the thermal fluctuations in the street by affecting mainly the wind conditions that contribute to moderate air temperature, sun and shade in streets. In this study, narrow and covered streets, at the orientations north-south, north west - south east, provide better shading by buildings, desirable at this region in summer, for pedestrians on sidewalks than wide streets, to ensure human thermal balance and guaranteed a level of thermal comfort, and the protection from the solar exposure is the more important objective related to the streets.

This opening to the sun is defined by a controlled SVF and an optimal $\mathrm{H} / \mathrm{W}$ ratio combined with a controlled solar orientation, favoring the North-South, North-West-South-East orientation which offers acceptable conditions in terms of comfort Compared with other solar orientations. Although the level of thermal comfort is a quantifiable and measurable element, its evaluation also requires consideration of the psychological aspect required for the control of perceived thermal sensation, using observation techniques, questionnaire and Surveys.

\section{References}

Ahmed Ouameur, F. (2007). Morphologie urbaine et confort thermique dans les espaces publics «Étude comparative entre trois tissus urbains de la ville de Québec». Mémoire pour l'obtention du grade de Maître en Sciences. Université Laval, Québec. 
Ali-Toudert, F., Djenane, M., Bensalem, R., Mayer, H. (2005-a). Outdoor thermal comfort in the old desert city of Beni-Isguen, Algeria, Climate Research, 28(3): 243-256.

Ali-Toudert, F., Mayer, H., (2005-b), Numerical study on the effects of aspect ratio and orientation of an urban street canyon on outdoor thermal comfort in hot and dry climate, Building and Environment, 41(2): 94-108.

Bourbia, F., Awbi, H., (2004), Building cluster and shading in urban canyon for hot dry climate, part 1: Air and surface temperature measurements, Renewable Energy, 29(2): 249-262.

Boussoualim, A., (2002), Contribution à la caractérisation de l'impact et de l'incidence du microclimat sur l'usage et les activités en espace public extérieur, Etude de cas à Blagnac, thèse de doctorat, Universite de Nantes.

Hamoud, A., Abdou, S., (2013), Approche d'une analyse syntaxique de l'habitat rural cas d'El Kantara, Courrier du Savoir (16) : 27-36.

Hamouda, A., Outtas, S., (2011), Etude topologique et diachronique de l'habitat rural : Cas D'el-Kantara, Biskra. Sciences \&Technologie, D(34): 28-37.

Höppe, P., (1999), The physiological equivalent temperature - a universal index for the biometeorological assessment of the thermal environment. International Journal of Biometeorology, 43(2): 71-75.

Johansson, E., (2006), Influence of urban geometry on outdoor thermal comfort in hot dry climate: A study in Fez, Morocco, Building and Environment, 41(10): 1326-1338.

Louafi, S., Abdou S., (2013), Benefits and well-being perceived by pedestrian in vegetated urban space in periods of heat stress, IACSIT International Journal of Engineering and Technology, 5(1):20-24.

Makaremi, N., Salleh, E., Jaafar, M.Z., Hoseini, A.H.G. (2012), Thermal comfort conditions of shaded outdoor spaces in hot and humid climate of Malaysia. Building and Environment, 48(1): 7-14.

Nikolopoulou, M, Steemers, K, (2003), Thermal comfort and psychological adaptation as a guide for designing urban spaces, Energy and Buildings, 35(1): 95-101.

Nikolopoulou. M, Baker. N, Steemers. K, (2001), Thermal comfort in outdoor urban spaces: understanding the human parameter, Solar Energy, 70(3): 227-235.

Stathopoulos, T., Wu, H., Zacharias, J., (2004), Outdoor human comfort in an urban climate, Building and Environment, 39(3): 297-305. 